\title{
Of primordial genomes and cooperative kittens
}

\section{Miranda Robertson}

Since every cell is derived from another cell, and the genetic code is more or less universal - so that life cannot, within the bounds of reasonable probability, have evolved more than once - every living being must ultimately derive from an ancestral cell containing a primordial genome. The recognition of the very large part played by horizontal gene transfer in the evolution of bacterial genomes has, however, lately (and notoriously) undermined any hope we may have cherished of tracing the branches of our genomic ancestry back to their prokaryotic roots. In this issue of Journal of Biology Eugene Koonin and colleagues [1] describe an analysis of phylogenetic trees for 6,901 bacterial genes on the basis of which they conclude that, ancestral gene-swapping notwithstanding, a vertical signal (sic) can in fact be discerned at the deepest levels in the phylogenetic tree, though it may never be possible to trace the branches.

The extraction of tree structures from the web of gene transfers requires that transferred genes be subtracted by some means from the database of genes used to construct the trees. In the minireview accompanying the paper, Kristen Swithers, Peter Gogarten and Gregory Fournier [2] explain the philosophies and hazards of the strategies for such subtraction, which include the danger of false vertical signals reflecting preferential gene transfer between bacterial species from quite separate branches of the phylogenetic tree and that happen to share a habitat [3]; and the distinct approach whereby Puigbò et al. [1] sought to circumvent the problems of finding the true tree in the thicket.
Whether because of horizontal gene transfer or the compression of branching events early in the evolution of prokaryotes, the lines of vertical descent derived by Puigbò et al. from their analysis defy resolution, at least for now and perhaps for ever. There is a character in the comic opera The Mikado, by WS Gilbert and Arthur Sullivan, who claims: 'I can trace my ancestry to a protoplasmal primordial atomic globule. Consequently my family pride is something inconceivable.' Inconceivable and probably misplaced, it would seem. The character is named, more appropriately even than Gilbert could have imagined, Pooh-Bah.

The Q\&A article in this issue, from James Ferrell Jr on cooperativity [4], belongs to the category of $\mathrm{Q} \& \mathrm{~A}$ articles that we have commissioned on concepts that are not necessarily new or even topical, but may be a source of confusion for many. We published our Q\&A on epistasis [5], for example, in the belief that many readers of papers on genome-scale analyses don't know what epistasis is and would find it useful. I suspect - though I may be wrong - that most readers think they do know what cooperativity is, more or less; but they may find, if they read Ferrell's beautifully navigated expedition through the possible and probable behavior of the subunits of haemoglobin, antibody binding to viral cell surfaces, and the tuning of signal-transducing G proteins, that cooperativity is more complicated and more interesting than they had realized.

And the kittens? Sleeping kittens are invoked to explain the Monod-
Wyman-Changeux model for cooperative binding of oxygen by hemoglobin, in which it is assumed that oxygen binding to one subunit has no effect on the affinity of the other subunits for oxygen, but that the conformational changes that increase or decrease oxygen affinity occur in unison. Readers who find the behavior of kittens easier to understand than the behavior of molecules may be encouraged by the analogy to read the non-kitten paragraphs too. (I recommend this.)

Purists who have no need of kittens will be gratified to note that allostery is implicitly defined by Ferrell as a conformational change at one site in a molecule induced by ligand binding at another site, and not, as in common usage, simply as a change in the conformation of the molecule.

Miranda Robertson, Editor editorial@jbiol.com

\section{References}

I. Puigbò P, Wolf YI, Koonin EV: Search for a 'Tree of Life' in the thicket of the phylogenetic forest. J Biol 2009, 8:59.

2. Swithers KS, Gogarten JP, Fournier GP: Trees in the Web of Life. J Biol 2009, 8:54.

3. Beiko RG, Harlow TJ, Ragan MA: Highways of gene sharing in prokaryotes. Proc. Natl. Acad. Sci USA 2005, 102: |4332-| 4337.

4. Ferrell JE Jr: Q\&A: Cooperativity. J Biol 2009, 8:53.

5. Roth PR, Lipshitz HD, Andrews BJ: Q\&A: Epistasis. J Biol 2009, 8:35.

Published: 20 July 2009

Journal of Biology 2009, 8:52.

(doi: 10.1 I86/jbioll63)

The electronic version of this article is the complete one and can be found online at http://jbiol.com/content/8/6/52

(c) 2009 BioMed Central Ltd 